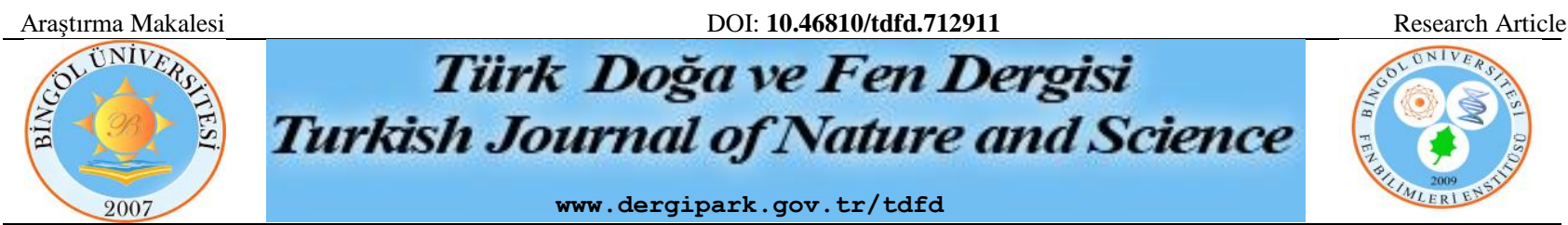

\title{
Cilt Lezyon Bölütlemesi için Metasezgisel Temelli Otsu Eşikleme Yöntemi
}

\author{
Nurullah ŞAHİN ${ }^{1}$, Nuh ALPASLAN ${ }^{2 *}$ \\ ${ }^{1}$ İnönü Üniversitesi, Mühendislik Fakültesi, Bilgisayar Mühendisliği Bölümü, Malatya, Türkiye \\ ${ }^{2}$ Bingöl Üniversitesi, Mühendislik ve Mimarlık Fakültesi, Bilgisayar Mühendisliği Bölümü, Bingöl, Türkiye \\ Nurullah ŞAHIN ORCID No: 0000-0002-3578-9959 \\ Nuh ALPASLAN ORCID No: 0000-0000-6828-755X \\ *Sorumlu yazar: nuhalpaslan@gmail.com
}

(Alınış: 01.04.2020, Kabul: 27.05.2020, Online Yayınlanma: 18.06.2020)

\begin{abstract}
Anahtar
Kelimeler

Melanom,

Otsu

Eşikleme,

Benzetimli

tavlama,

Melodi

arama

Öz: Melanom yapısal DNA hasarından kaynaklı en ölümcül cilt kanseri türlerinden olmakla beraber erken tanı konulması durumunda hayatta kalma oranı oldukça yüksektir. Melanom teşhisi, lezyon bölgesine ait dermoskopi görüntülerinin dermatolog tarafindan görsel olarak incelenmesi ile konulur. Kesin tanı ise lezyon bölgesinden doku örneği alınıp patolojik inceleme sonrası ortaya çıkmaktadır. Patolojik inceleme hem çok zaman alan hem de maliyetli bir yöntemdir. Dermatologlar tarafından yapılabilecek hataları en aza indirmek ve melanomun doğru teşhisi için hekime yardımcı olmak amacıyla çok sayıda bilgisayar destekli tanı sistemi geliştirilmiştir. Lezyon bölgesinin doğru biçimde bölütlenmesi, özellik çıkarımı ve sınıflandırma performansını doğrudan etkilediği için kritik öneme sahiptir. Bu çalışmada öncelikle yeniden boyutlandırma, siyah çerçeve silme ve kıl silme gibi bir dizi önişleme adımı uygulanmıştır. Daha sonra gri seviyeye dönüştürülmüş görüntünün histogramı elde edilerek lezyon bölgesini sağlıklı cilt bölgesinden ayırmak için uygun eșik değeri geleneksel Otsu, Otsu tabanlı HA, SA ve PSO yöntemleri ile elde edilmiştir. Bulunan en uygun eşik değerine göre görüntü ikili görüntüye dönüştürülerek nihai lezyon bölgesi elde edilir. Sonuç olarak, ortalama iterasyon sayılarına göre çalışma süresi hesaplandığında, PSO, HA, SA yöntemlerinin bölütleme başarımından ödün vermeden geleneksel Otsu yöntemine göre sırasıyla \%40, \%29 ve \%28.5 daha hızlı optimal eşik değerini bulduğu gözlemlenmiştir.
\end{abstract}

\section{Metaheuristic Based Otsu Thresholding Method for Skin Lesion Segmentation}

\section{Keywords Melanoma Otsu \\ Threshold, Simulated Annealing, Melody Search}

\begin{abstract}
The melanoma is one of the most fatal type of skin cancer which is caused by structural DNA damage. But in case of early diagnosis, the survival rate is pretty high. The melanoma diagnosis is made by visual examination of the dermoscopy images of the lesion area by a dermatologist. The exact diagnosis is obtained after pathological examination by taking tissue sample from the lesion area. The pathological examination is a very time-consuming and costly method. Numerous computer-aided diagnostic systems have been developed to minimize errors that can be made by dermatologists and to assist the physicians in the correct diagnosis of melanoma. The accurate segmentation of the lesion is critical as it directly affects feature extraction and classification performance. In this study, firstly a number of preprocessing steps, such as resizing, black-frame, and hair removal, were carried out. Then, the histogram of grayscale converted image is obtained and traditional Otsu, Otsu based HS, SA and PSO methods were applied to find the optimal threshold value to segment the lesion area from healthy skin. The final lesion area is obtained by transforming the image into a binary image according to the optimal threshold value. As a result, when the working time is calculated according to the average number of iterations, PSO, HS, SA methods have been observed to find the optimal threshold value $40 \%, 29 \%$ and $28.5 \%$ faster than the traditional Otsu method, without compromising the segmentation performance.
\end{abstract}




\section{GíRIŞ̧}

Kötü huylu melanom en yaygın cilt kanseri türlerinden biri olup yayılımı son yıllarda gittikçe artmaktadır. Bununla birlikte melanom erken teşhis edildiği taktirde hayatta kalma ve iyileşme oranı oldukça artmaktadır [1]. Cilt kanseri tanısında yaygın olarak dermoskopi yöntemi kullanılmaktadır. Dermoskopi, cilt lezyonlarının incelenmesinde hekime yardımcı olmak için polarize 1 şık kullanan invazif olmayan bir görüntüleme yöntemidir [2]. Dermatologlar, melanoma tespiti için ABCD kuralı [3], 7 noktalı kontrol listesi [4], menzies yöntemi gibi çeşitli prosedürler kullanırlar [5]. Bu prosedürler genel olarak lezyon bölgesinin rengi, geometrisi, yapısal ve dokusal özellikleri üzerinde yoğunlaşır. Dermoskopi her ne kadar cilt lezyon sınıflandırılmasında başarılı bir yöntem olsa da doğru sinıflandırma başarısı dermatoloğun tecrübesine ve dikkatine bağlıdır. Lezyon sınıflandırmasındaki bu sorunlar ile baş edebilmek adına çok sayıda bilgisayar destekli tanı sistemleri geliştirilmiştir. Lezyon sınıflandırmasında kullanılan bilgisayar destekli tanı sistemleri temel olarak dört adımdan oluşur; 1) tüy silme ve yumuşatma, 2) bölütleme, 3) öznitelik çıkarımı ve uygun özelliklerin seçimi, 4) sınıflandırma [6].

Lezyon görüntülerinde bölütleme adımı, özellik çıkarımı ve sınıflandırma adımlarının performansını doğrudan etkilediğinden kritik öneme sahiptir. Cilt lezyonlarında bölütleme adımı cilt üzerindeki kıl ve hava kabarcıkları, cilt lezyonlarının renk dağılımlarındaki farklılıklar, sınır düzensizlikleri ve düşük kontrast gibi çeşitli olumsuz koșullardan ötürü zor bir süreçtir. Sekil 1'de farklı zorluktaki cilt lezyon türleri görülmektedir. Literatürde cilt lezyon bölütlemesi için çeşitli yöntemler önerilmiştir. Bunlardan bir kısmı; eşikleme [7], bölütleme için piksel komșuluk değerlerine bakarak pikselleri sınıflandıran, bölge büyütme yöntemi [8], seviye belirleme yöntemi [9], kümeleme algoritmaları [10], geodezik aktif veya bölge tabanlı kontur modelleri, istatistiksel bölge birleştirme [11] yöntemleridir. Eşikleme tabanlı yöntemler düşük kontrast değerlerinde düşük performans göstermelerine rağmen kolay uygulanabilirlikleri ve hizlı tepki vermelerinden dolayı yaygın biçimde kullanılmaktadır. [6], global eşikleme yerine görüntünün alt görüntülere bölündüğü ve alt görüntüler için ayrı ayrı eşik değerlerinin hesaplandığı adaptif bir otomatik eşikleme yöntemi önermiştir. [12], görüntünün histogramını çıararak, histogram eşiklemesine dayalı bir otomatik eşikleme yöntemi önermiştir. [13], arıların yiyecek bulmada birbirleriyle haberleşmelerinden esinlenerek metasezgisel yöntem olan yapay arı kolonisi kullanan bir global eşikleme yöntemi önermiştir.

Bu çalışmada cilt lezyon bölütlemesi için, sınıflar arası varyans ölçütü kullanan eşikleme tabanlı bir yöntem olan Otsu yöntemi, minimizasyon problemine dönüştürülerek, parçacık sürü optimizasyonu (particle swarm optimization, PSO), harmoni arama (harmony search, HS) ve benzetimli tavlama (simulated annealing, SA) metasezgisel yöntemleri ile gerçeklenir. Lezyon bölütleme hızını arttırmak için öncelikle görüntüler yeniden boyutlandırılır. Yeniden boyutlandırılan görüntüye kıl silme algoritması uygulanır. Elde edilen görüntüyü ikili forma dönüştürmeden önce optimal eşik değerini bulmak için parçacık sürü optimizasyonu, harmoni arama, ve benzetimli tavlama ve klasik Otsu yöntemleri kullanılır ve elde edilen optimal eşik değerine göre görüntü ikili forma dönüştürülür. Elde edilen sonuçlar, uzman tarafindan belirlenen kesin referans sonuçları ile karşılaştırılarak bölütleme başarımları hesaplanır. Son olarak, kullanılan metasezgisel yöntemlerin bölütleme başarımları ve bölütleme süreleri, birbirleriyle ve klasik Otsu yöntemiyle karşılaştırılır. Eşikleme metodlarının metasezgisel yaklaşımlarla bölütlenmesinin literatürde örnekleri olmakla beraber cilt lezyonları üzerinde çok fazla çalışma yoktur. Bu çalışmada, bilindiği kadarı ile cilt lezyon otsu yöntemi ile eşiklemesinde optimal eşik değerinin elde edilmesinde HA yöntemi ilk defa kullanılmıştır. Ayrıca çalışmanın diğer bir özgün yanı cilt lezyon bölütlemesinde klasik otsu ile metasezgisel yöntemlerin karşılaştırılmasının yanı sıra sürü tabanlı metasezgisel yöntemler ile sürü tabanlı olmayan metasezgisel yöntemlerin de birbirleri ile karşılaştırmasının yapılması olup, cilt lezyonları için bu kapsamda yapılmış ilk çalışmadır. Çalışmanın kalanı şu şekilde organize edilmiştir. Bölüm 2'de Parçacık Sürü Optimizasyonu, Benzetilmiş Tavlama ve Harmoni Arama ile ilgili kısaca bilgi verilmiştir. Bölüm 3'te yöntemimizden kısaca bahsedilmiştir. Bölüm 4'te ISIC veri kümesinden alınan görüntüler kullanılarak bölütleme işleminin sonuçları paylaşılmıştır. Son olarak bölüm 5'de elde edilen sonuçlar tartışılmıştır.

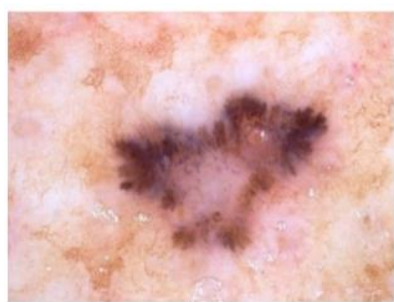

(a)

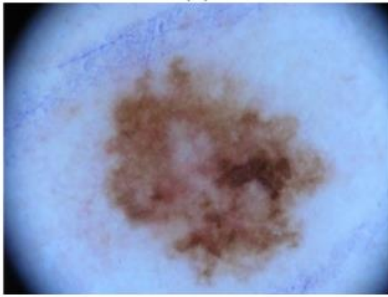

(c)

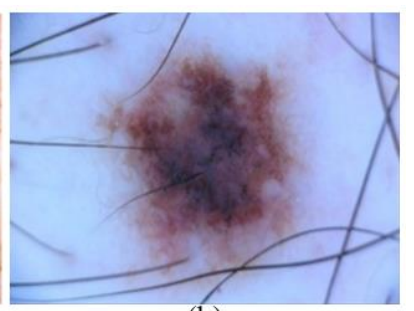

(b)

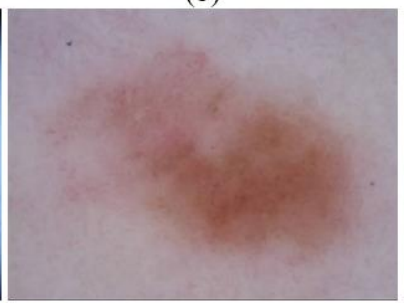

(d)
Sekil 1. Farklı cilt lezyon tipleri; a) düzensiz sınırlar, b) deri üstünde kıl, c) siyah çerçeveler, d) lezyon bölge ile sağlıklı cilt arasında düșük kontrast fark1.

\section{2. İLGİLİ ÇALIŞMALAR}

\subsection{Parçacık Sürü Optimizasyonu}

PSO sürü halinde hareket eden bazı hayvanların yiyecek bulmak gibi temel ihtiyaçlarını giderirken sergiledikleri hareketlerin, sürüdeki diğer bireyleri etkilediğinin ve sürünün amacına daha kolay ulaştığının gözlemlenmesinden esinlenilerek Dr. Kennedy ve Dr. 
Eberhart tarafından geliştirilen popülasyon temelli metasezgisel bir optimizasyon yöntemidir [14]. Sürülerde bireyler birbirleri ile iletişim halindedir. Sürüde bir birey yiyecek bulduğu zaman, sürüdeki diğer bireylerin de yiyeceğin olduğu konuma göre konumlarını ve hızlarını güncelledikleri gözlemlenmiştir. PSO bu sürü hareketini örnek almaktadır. Sürüdeki her birey bu yöntemde parçacık olarak tanımlanmaktadır. Koordinatlara rastgele serpiştirilen parçacıklar en iyi çözüm değerine ulaşmayı amaçlarken, bu çözüm değerine ulaşana kadar önceki bilgileri tutarak elde ettikleri geçici çözüm değerleri ile tuttukları konum ve hız bilgilerini güncellemektedir [15]. Parçacık sürü optimizasyonu yöntemi şu adımlardan oluşmaktadır;

1) Parçacıklar rastgele hız değerleri verilerek rastgele koordinatlara serpiştirilirler ve ardından her parçacık için uygunluk değeri hesaplanır.

2) Her bir parçacık için yerel en iyi pozisyon $\left(p_{i}\right)$ ve sürüdeki tüm parçacıklara bakılarak genel en iyi pozisyon $\left(z_{i}\right)$ bulunur. Denklem (1) yerel en iyiyi, denklem (2) genel en iyiyi göstermektedir.

$$
\begin{aligned}
& p_{i}(t+1)= \begin{cases}p_{i}(t), i s e & f\left(x_{i}(t+1)\right) \geq f\left(p_{i}(t)\right) \\
x_{i}(t+1) & \text {,ise } \quad f\left(x_{i}(t+1)\right)<f\left(p_{i}(t)\right)\end{cases} \\
& z_{i}(t) \in\left\{p_{1}(t), p_{2}(t), \ldots, p_{m}(t)\right\}= \\
& \min \left\{f\left(p_{1}(t)\right), f\left(p_{2}(t)\right), \ldots f\left(p_{m}(t)\right)\right\}
\end{aligned}
$$

3) Parçacıkların pozisyon ve hızları denklem (3) ve denklem (4) kullanılarak güncellenir. Denklem (3)'te $w$; eylemsizlik, $r_{1}$ ve $r_{2} 0$ ile 1 aralığında seçilen rastgele sayıları, $c_{1}$ ve $c_{2}$ ivmelenme katsayılarını ifade etmektedir.

$$
\begin{gathered}
v_{i}(t+1)=w v_{i}(t)+c_{1} r_{1}\left(p_{i}(t)-x_{i}(t)\right)+c_{2} r_{2}\left(z_{i}(t)-x_{i}(t)\right) \\
x_{i}(t+1)=x_{i}(t)+v_{i}(t+1)
\end{gathered}
$$

4) Verilen durdurma kriteri sağlanıncaya kadar adım 1, 2 ve 3 her iterasyonda tekrarlanır.

\subsection{Benzetimli Tavlama}

Benzetimli tavlama yöntemi, demirin 1sıtılması anlamına gelen tavlama işleminden esinlenerek geliştirilmiş ve optimizasyon problemlerinde kullanılmaya başlanmıştır [16]. Metallerin tavlanma işlemi ile optimizasyon sürecindeki olası çözüm uzayı arasında benzerlikten ilham alınarak oluşturulmuştur. $\omega, \Omega$ çözüm uzayında bir başlangıç noktası olsun. $f: \Omega \rightarrow R$ çözüm uzayında tanımlı amaç fonksiyonumuz olmak üzere, SA yöntemi $T=t_{0} \geq 0$ başlangıç sicaklığında rastgele bir $\omega$ başlangıç noktası ile başlatılır. Daha sonra bir $N$ komşuluk fonksiyonu ile $\omega$ mevcut çözüm değerinden bir $\omega^{\prime} \in N(\omega)$ aday çözüm değeri üretilir. $f(\omega)$ 'den $f\left(\omega^{\prime}\right)$ 'ne değişim istenen yönde ise komşu çözüm mevcut çözüm olarak güncellenir. Değişim istenen yönde olmadı̆̆ı durumda ise SA bu yeni çözümü "Metropolis Kriteri" ile elde edilen olasılık değeri ile kabul etmektedir [17]. Bu aşama SA'nın temel kısmını oluşturur ve yöntemin yerel en iyiye takılıp kalmasını önlemektedir. Denklem (5) $\omega^{\prime} \in N(\omega)$ 'nin mevcut çözüm olarak şeçilme olasılığını belirtmektedir.

$P\left(\omega^{\prime}\right)=\left\{\begin{array}{lll}\exp \left[-\left(f\left(\omega^{\prime}\right)-f(\omega)\right) / t_{k}\right] & \text { if } & f\left(\omega^{\prime}\right)-f(\omega) \geq 0 \\ 1 & \text { if } & f\left(\omega^{\prime}\right)-f(\omega) \leq 0\end{array}\right.$

Burada $k$ sıcaklık değişim sayacını; $t_{k}$, sıcaklık değişim çizelgesini; $P\left(\omega^{\prime}\right) \quad \omega^{\prime}$ aday çözümünün mevcut çözüm olarak seçilme olasılığını ve $\omega, \Omega$ çözüm uzayında bir başlangıç noktasını, $\omega$ ' ise $\omega$ 'nin komşuluğunda elde edilen aday çözümü ifade etmektedir. Yöntemin adımları genel hatlarıyla şu şekilde ifade edilebilir;

1) $T$ için başlangıç değeri seçilir.

2) $\Omega$ çözüm uzayında rastgele $\omega$, başlangıç noktası seçilir, $f(\omega)$ hesaplanır.

3) $\quad N$ komşuluk fonksiyonu ile $\omega$ mevcut çözüm değerinden bir $\omega^{\prime} \in N(\omega)$ aday çözüm değeri üretilir.

4) $f\left(\omega^{\prime}\right)<f(\omega)$ ise hareket kabul edilir, değilse metropolis kriterine göre kabul edilme olasılığı oluşturulur.

5) Adım 3 ve adım 4 yeni aday çözümler için tekrarlanir.

6) Amaç fonksiyonu minimum yapan $\omega^{*}$ değeri bulunur.

7) $T$ sıcaklık değeri azaltılır.

8) Yeni $T$ sıcaklığı için adım 2 ile adım 6 arası tekrarlanır.

9) Verilen durdurma koşulu sağlandığında algoritma sonlanir.

\subsection{Harmoni Arama}

[18] tarafından önerilen algoritma, müzikteki notalardan esinlenerek geliştirilmiş metasezgisel bir algoritmadır. Müzisyenlerin çaldıkları notalar ile harmonik açıdan en iyi melodiye ulaşılması hedeflenmektedir. Notaların bir araya gelmesiyle oluşturulan her harmoni bir geçici çözümü temsil etmektedir. Bu şekilde en iyi çözümü verecek olan harmoni bulunmaya çalışılır. HA'nın kullandığ̀ parametreler; Harmoni belleği kapasitesi (Harmony Memory Size, HMS), harmoni belleğini dikkate alma oranı (HMCR, Harmony Memory Consideration Rate) ve ton ayarlama oranıdır (PAR, Pitch Adjustment Rate). HA algoritması, genel olarak şu adımları içerir [19];

Adım 1: Problemin tespiti ve HA parametrelerinin oluşturulması.

Adım 2: HA için hafızanın oluşturulması. 


$$
\left[\begin{array}{cccc}
x_{1}^{1} & x_{2}^{1} & \ldots & x_{N}^{1} \\
x_{1}^{1} & x_{2}^{2} & \ldots & x_{N}^{2} \\
\ldots & \ldots & \ldots & \ldots \\
x_{1}^{H M S} & x_{2}^{H M S} & \ldots & x_{N}^{H M S}
\end{array}\right]=\left[\begin{array}{c}
f\left(x^{1}\right) \\
f\left(x^{2}\right) \\
\ldots \\
f\left(x^{H M S}\right)
\end{array}\right]
$$

Burada $x$ çözüm uzayındaki değerleri, $f$ ise çözüm uzayındaki değerlerle oluşturulan her bir harmoni için amaç fonksiyonu ifade etmektedir. Algoritmada her bir çözüme karşılık gelen amaç fonksiyonu değerleri denklem (6)'ya göre hesaplanır.

Adım 3: Yeni harmoni oluşturulması. Burada HMCR parametresi kullanılarak, çözüm uzayındaki bir değerin harmoni belleğinden mi seçileceğini yoksa çözüm uzayından yeni değerin mi seçileceği hesaplanır; Bu seçim denklem (7)'de gösterilmiştir.

$$
x_{i}^{\prime}= \begin{cases}x_{i}^{\prime} \in\left\{x_{i}^{1}, x_{i}^{2}, \ldots, x_{i}^{H M S}\right. & \} \text { HMCR } \text { olurluk durumu } \\ x_{i}^{\prime} \in X_{i} & \text { diger durum }\end{cases}
$$

Yapılan seçimin ardından yeni harmoni vektörüne eklenen her bir değerin tonlamaya ihtiyaç duyup duymadığı belirlenir, bunun için PAR parametresi kullanılır. Denklem (8) tonlama işlemini ifade etmektedir.

$$
x_{i}^{\prime}=\left\{\begin{array}{lr}
x^{\prime} \pm \operatorname{Rnd}(0 ; 1) * b w & \text { PAR } \\
x_{i}^{\prime} & \text { diger }
\end{array}\right.
$$

Denklem (8)'de, $b w$ rastgele seçilmiş bant genişliğini; $\operatorname{rnd}(0 ; 1), 0$ ile 1 arasında üretilmiş rastgele sayıyı temsil etmektedir. HMCR ve PAR adımlarının ardından uygunluk değerine sahip yeni harmoni $x^{\prime}=\left(x_{1}^{\prime}, x_{2}^{\prime}, \ldots, x_{N}^{\prime}\right)$ oluşturulmuş olur.

Adım 4: Yeni oluşturulan harmoni bellekteki en kötü harmoniden daha iyi sonuç veriyorsa, bellekteki en kötü harmoni atılarak yeni harmoni eklenir. Sonlandırma koşulu sağlanana kadar adım 3 ve adım 4 tekrarlanır.

\section{3. ÖNERILEN YÖNTEM}

$\mathrm{Bu}$ bölümde optimal eşik değerini hesaplamak için önerilen algoritma ifade edilmiştir. İlk olarak, görüntü histogramından tüm fonksiyon parametrelerinin tahmin edilmesi önemlidir. Önerilen yöntemde bu problem PSO, HA ve SA optimizasyon algoritmaları tarafindan en aza indirgenen bir amaç fonksiyonu optimize edilerek çözülmüştür. Sonra optimal eşik değeri hesaplanan parametrelerle belirlenmiştir.

Çalışmamızda, yeniden boyutlandırılan ve kıl silme algoritması uygulanan görüntü, gri seviye görüntü $g(x, y)$ 'ye dönüştürülür. Elde edilen $g(x, y)$ gri seviye görüntünün histogramı oluşturulur. Oluşturulan $C=[1, L]$ histogramında $L$ adet gri seviye değeri olduğunu kabul edersek, gri seviye görüntüsündeki, 1 ile $L$ arasındaki herhangi bir $i$ gri seviye değerine sahip olan piksel sayısı $c_{i}$ ile gösterilebilir. Burada, görüntü histogramının alınması ek işlem gibi görünse de otsu hesaplamasında ve PSO, HA, SA ile en iyi eşik değerini bulmak için kullanılacak amaç fonksiyon hesaplanması aşamalarında işlem yükünün azaltılmasında oldukça önemlidir. Görüntü histogramı çıkarıldıktan sonra, histogram kullanılarak görüntüyü lezyon $\left(C_{0}=\left[c_{1} c_{2} \ldots c_{k}\right]\right)$ ve lezyon olmayan $\left(C_{1}=\left[c_{k+1} c_{k+2} \ldots c_{L}\right]\right)$ bölgelere en iyi şekilde ayırabilmek için, optimal $k$ değeri hesaplanır. Bunun için varyans bilgisi kullanılmıştır. Klasik Otsu yöntemi uygulanırken, sınıflar arası varyans $\left(\sigma_{B}^{2}\right)$ değerini maksimum yapan eşik değeri aranırken, çalışmamızda toplam varyans ile sınıflar arası varyans değeri arasındaki farkı $\left(\sigma_{T}^{2}-\sigma_{B}^{2}\right)$ minimum yapan değer aranmıştır. Burada $\sigma_{T}^{2}-\sigma_{B}^{2}$ değerini amaç fonksiyon olarak kullanarak, klasik otsu yöntemimize ek bir hesaplama yükü getirmeden, klasik otsu ile maksimizasyon problemi olarak ele alınan optimum eşiği bulma problemi, $\mathrm{PSO}, \mathrm{HO}$ ve SA yöntemleri için minimizasyon problemine dönüştürülmüştür. Denklem (9) ve (10) klasik otsu metodu için amaç fonksiyonunu, denklem (11) ve (12) metasezgisel yöntemlerimiz için kullandığımız amaç fonksiyonunu ifade etmektedir. Denklem (13) ve (14) sırasıyla sınıflar arası varyans değerinin ve toplam varyansın hesaplanmasını göstermektedir. Otsu yönteminde toplam varyans görüntü için sabit olduğu için, ağırlıklı sınıf içi varyansı azaltmak sınıflar arası varyansı arttırırken tersi durumda sınıflar arası varyansı azaltmaktadır.

\subsection{Amaç Fonksiyonu ve Eşik Değeri}

Otsu, gri seviye görüntüler üzerinde varyansa göre eşikleme yapabilmemizi sağlayan bir yöntemdir [20]. Bu yöntemde, görüntünün arka plan ve ön plan olmak üzere iki renk sınıfından oluştuğu varsayımı yapılır. Daha sonra tüm eşik değerleri için bu iki renk sınıfının sınıf içi varyans değeri yada sinıflar arası varyans değeri hesaplanır. Toplam varyansın değişmediği göz önünde bulundurularak, ağırlıklı sınıf içi varyans değerini minimum yapan yada sınıflar arası varyans değerini maksimum yapan değer en uygun eşik değeri olarak alınır. Çalışmada hesaplama kolaylığı için sınıflar arası varyans değeri maksimize edildi ve metasezgisel yöntemler için ise $\sigma_{T}^{2}-\sigma_{B}^{2}$ değeri minimize edilmiştir.

$$
\begin{gathered}
k^{*}=\operatorname{argmax} \sigma_{B}^{2}(k) 1 \prec k \prec L \\
k^{* *}=\operatorname{argmin}\left(\sigma_{T}^{2}-\sigma_{B}^{2}(k)\right) \\
\sigma_{B}^{2}=P\left(C_{0}\right) P\left(C_{1}\right)\left(\mu_{0}-\mu_{1}\right)^{2} \\
\sigma_{T}^{2}=\sigma_{B}^{2}+\sigma_{W}^{2}
\end{gathered}
$$

Denklem (9)'da $k^{*}$ sinıflar arası varyansı maksimum yapan $k$ eşik değerini ifade etmektedir. Denklem 
(10)'da $k^{* *} \sigma_{T}^{2}-\sigma_{B}^{2}$ değerini minimum yapan eşik değerini ifade etmektedir. Denklem (11)'de, $C_{0}$ birinci sınıfın olasılığını, $\quad C_{1}$ ikinci sınıfinın olasıllığını ifade etmektedir. Denklem (12)'de $\sigma_{W}^{2}$ ağırlıklı sınıf içi varyans değerini ifade etmektedir. Önerilen yönteme ait akış şeması Şekil 2'de gösterilmiştir.

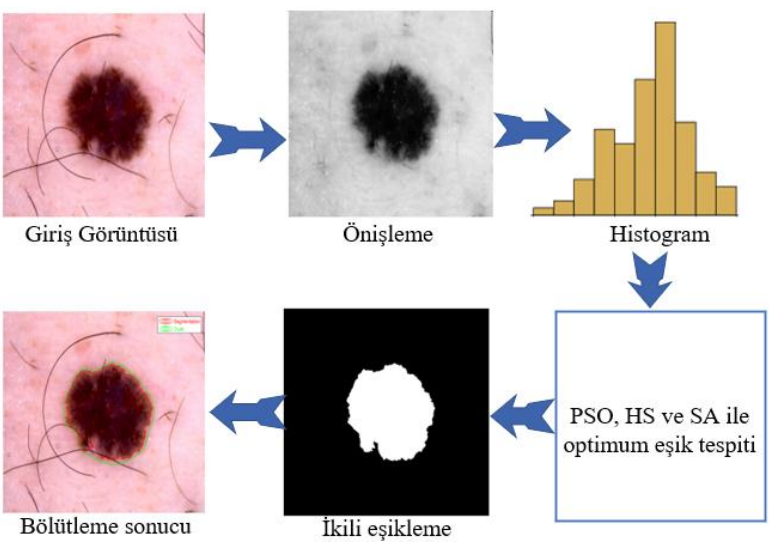

Şekil 2. Önerilen yönteme ait akış şeması

\section{DENEYSEL SONUÇLAR}

Çalışma Intel(R) Core(TM) i5-8300 CPU @ 2.3GHZ, 8GB RAM kullanan bilgisayarda ve ISBI2016 lezyon veri setinden elde edilen 10 adet görüntü üzerinde gerçekleştirilmiş̧ir. Şekil 3'te çalışmada kullanılan örnek görüntüler verilmiştir. Otsu yönteminde sınıflar arası varyansı maksimum yapan eşik değeri hesaplanarak problem maksimizasyon problemi olarak hesaplanırken; PSO, HA, SA yöntemlerinde amaç fonksiyon olarak
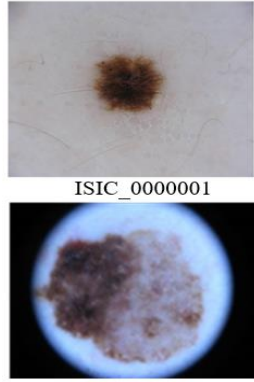

ISIC_0000036

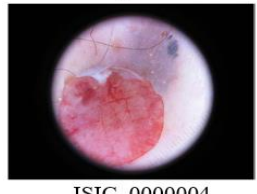

ISIC 0000004

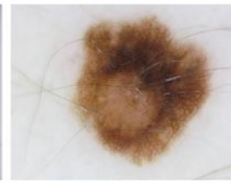

ISIC_0000003
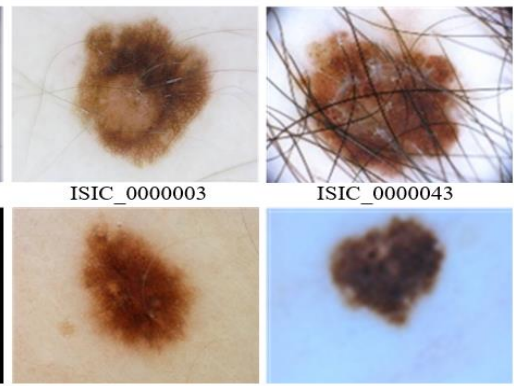

ISIC_0000082

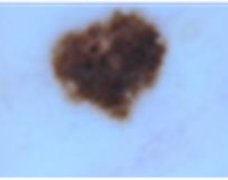

ISIC_0000016

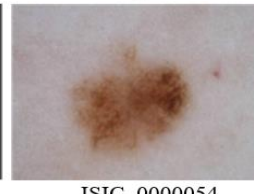

ISIC 0000054

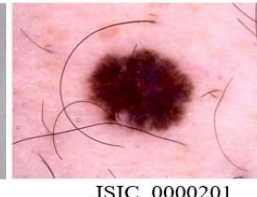

ISIC 0000201

Şekil 3. Deneysel çalışmalarda kullanılan örnek görüntüler

hesaplanan toplam varyans ile hesaplanan sinıflar arası varyans değerleri farkını minimum yapan değer hesaplanarak, problem minimizasyon problemi olarak ele alınmıştır.

Şekil 4'te maksimum varyası arayan Otsu yöntemi ve minimum amaç fonksiyon değerini arayan $\mathrm{PSO}$, HA ve SA yöntemlerinin optimal eşiği arama adımları gösterilmiştir. Burada, yatay eksen iterasyon sayısını, dikey eksen Otsu yöntemi için sınıflar arası varyans değerini $\left(\sigma_{B}^{2}\right)$, PSO, HA, SA için ise grafikte en iyi maliyet olarak isimlendirilen, optimizasyon işlemi için amaç fonksiyonumuz olan toplam varyans ile sinıflar arası varyans değeri arasındaki fark yani $\sigma_{T}^{2}-\sigma_{B}^{2}$ değerini ifade etmektedir.

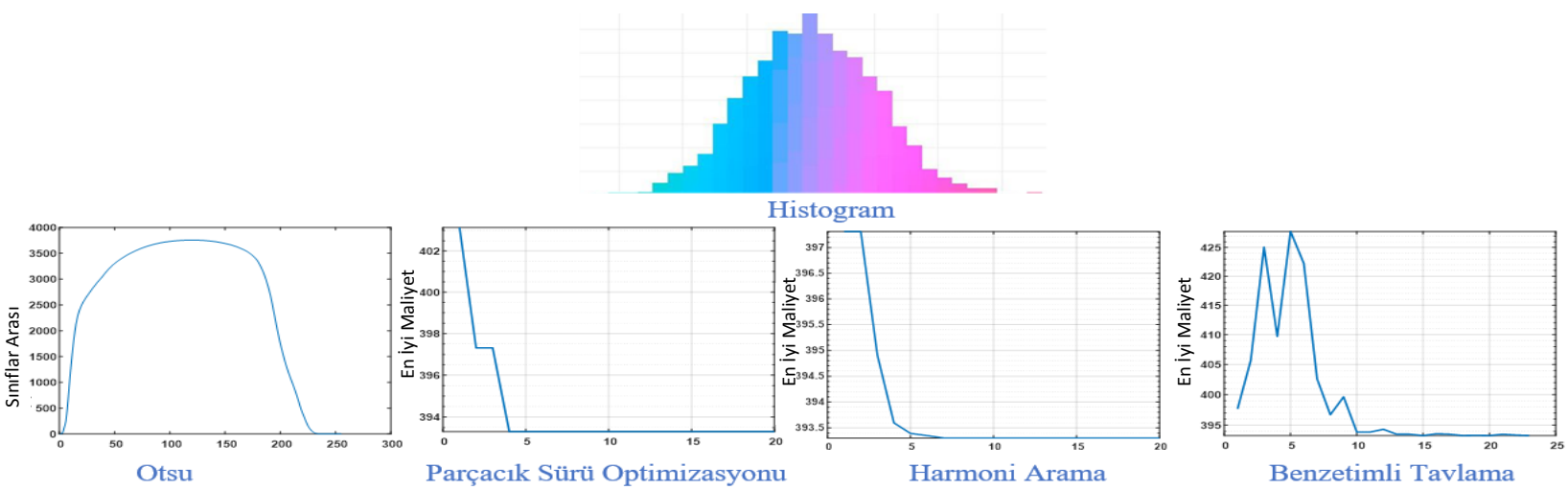

Şekil 4. Otsu, PSO, HA, SA yöntemleri ile optimal eşik değerinin belirlenip ikili görüntü oluşturulması.

PSO algoritması için parçacık sayısı=10, maksimum iterasyon sayıs $=20$, birey ivmelenmesi $=2$ ve popülasyon ivmelenmesi=2 olarak alınmıştır. HA algoritması için maksimum iterasyon sayıs $=20, \mathrm{HMS}=10, \mathrm{HMCR}=0.8$, $\mathrm{PAR}=0.4$ seçilmiştir. SA algoritmasında başlangıç sicaklığ $1 \mathrm{~T}=100$, soğutma değeri $=\mathrm{T}^{*} 0.7$ ve durma sıcaklığ $1=(1 \mathrm{e}-2) * 4$ olarak seçilip verilen parametrelere göre yöntem 23 farklı sıcaklık değeri dolayısı ile 23 iterasyon çalıştırılmıştır. Çalışmada parametre seçimi deneysel olarak ve adil karşılaştırmaya uygun olacak şekilde seçilmiştir. Başarım ölçütü olarak dice benzerliği, kosinüs benzerliği ve hesaplama süresi (computation time) göz önüne alınmıştır.
Tablo 1 sırası ile klasik Otsu eşikleme, PSO, HA, SA yöntemlerinin Dice ve Kosinüs benzerlik sonuçlarını göstermektedir. Klasik Otsu eşiklemesi, Otsu temelli PSO, HA ve SA yöntemlerinin hesaplama süresi saniye cinsinden Şekil 5'te sunulmuştur. Tablo 2; PSO, HA ve SA algoritmalarının optimal eşiği bulduğu en düşük, en yüksek ve ortalama iterasyon sayısını göstermektedir. Şekil 5, Tablo 2'teki ortalama iterasyon sayıları göz önüne alındığında elde edilen hesaplama sürelerini göstermektedir. 
Tablo 1. ISIC veri setine ait örnek görüntüler için, geleneksel Otsu ve Otsu temelli PSO, HA, SA için dice ve kosinüs benzerliği sonuçları

\begin{tabular}{|c|c|c|c|c|c|c|c|c|}
\hline & Dice-Otsu & Dice-PSO & Dice-HA & Dice-SA & Cosine-Otsu & Cosine-PSO & Cosine-HA & Cosine-SA \\
\hline ISIC_0000001 & 98,03 & 98,05 & 98,07 & 98,06 & 98,04 & 98,06 & 98,07 & 98,07 \\
\hline ISIC_0000003 & 95,85 & 95,88 & 95,88 & 95,93 & 95,93 & 95,96 & 95,96 & 96,01 \\
\hline ISIC_0000004 & 94,99 & 94,99 & 94,99 & 94,99 & 95 & 95 & 95 & 95 \\
\hline ISIC_0000013 & 95 & 94,97 & 94,98 & 95,07 & 95,12 & 95,09 & 95,1 & 95,19 \\
\hline ISIC_0000016 & 93,6 & 93,63 & 93,62 & 93,63 & 93,79 & 93,82 & 93,81 & 93,82 \\
\hline ISIC_0000036 & 64,17 & 64,15 & 64,17 & 64,06 & 67,58 & 67,57 & 67,59 & 67,51 \\
\hline ISIC_0000043 & 92,77 & 92,77 & 92,74 & 92,75 & 92,84 & 92,84 & 92,81 & 92,82 \\
\hline ISIC_0000054 & 85,66 & 85,79 & 85,68 & 85,72 & 86,55 & 86,67 & 86,57 & 86,61 \\
\hline ISIC_0000082 & 88,06 & 87,97 & 88,17 & 88,17 & 88,69 & 88,61 & 88,79 & 88,79 \\
\hline ISIC_0000201 & 93,48 & 93,53 & 93,53 & 93,49 & 93,68 & 93,72 & 93,73 & 93,69 \\
\hline Average & 90,161 & 90,173 & 90,183 & 90,187 & 90,722 & 90,734 & 90,743 & 90,751 \\
\hline
\end{tabular}

Tablo 1'den görüldüğü üzere, kullanılan metasezgisel yöntemler en uygun eşik değerini bulmada Otsu yöntemi ile benzer sonuçlar elde etmişlerdir. Ancak Şekil 5'te elde edilen zaman sonuçları incelendiğinde ise metasezgisel yöntemlerin geleneksel Otsu yöntemine göre daha kısa sürede sonuç ürettiği görülmektedir. Bununla birlikte SA, PSO ve HA yöntemlerinin geleneksel Otsu yöntemine göre sırasıyla yaklaşık \%18, $\% 12$ ve $\% 7$ daha hızlı optimal eşik değerini bulduğu gözlemlenmiştir.

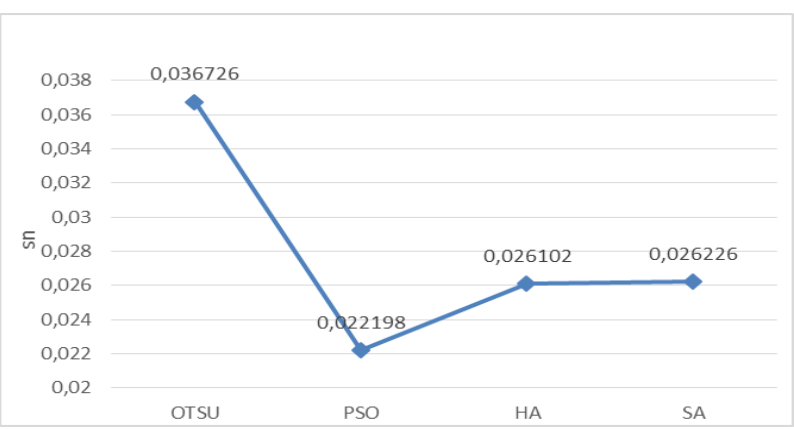

Şekil 5. Yöntemlerin en iyi eşik değerini bulmak için ortalama hesaplama süreleri

Şekil 6'da 20 iterasyon için hesaplama sürelerine bakıldığında en iyi hesaplama süresinin PSO'da en kötü hesaplama süresinin geleneksel Otsu metoduna ait olduğu gözlemlenmiştir. SA algoritmasının HO'ya göre nispeten daha iyi sonuç verdiği gözlemlenmiştir. Şekil 6'da dikkat çeken bir nokta ISIC_0000004 için Otsu için hesaplama süresinin dikkate değer biçimde düşmesidir. Ancak resmin histogramı incelendiğinde bunun resimdeki gri seviye değerlerinin az olmasından kaynaklandığı dolayısı ile bunun hesaplama süresini düşürdüğü gözlemlenmiştir.

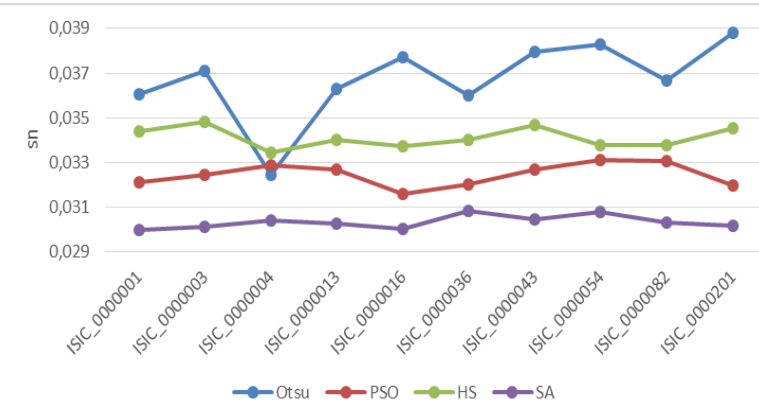

Şekil 6. Örnek görüntülerle, 20 iterasyon için hesaplama süreleri
Tablo 2. PSO,HA ve SA yöntemlerinin en iyi eșik değerini bulmak için gereken en az, en çok ve ortalama iterasyon sayıları

\begin{tabular}{|c|c|c|c|}
\hline & PSO & HA & SA \\
\hline En Az & 2 & 2 & 8 \\
\hline En Çok & 7 & 7 & 22 \\
\hline Ortalama & 4,3 & 5,1 & 17,3 \\
\hline
\end{tabular}

Tablo 2'deki ortalama iterasyon sayısı PSO için 4, HA için 5 ve SA için 17 olarak alınmış ve ortalama iterasyon sayılarına göre çalışma süresi hesaplanmıştır. PSO, HA, SA yöntemlerinin geleneksel Otsu yöntemine göre sırasıyla \%40, \%29 ve \%28.5 daha hızlı optimal eşik değerini bulduğu gözlemlenmiştir.

\section{TARTIŞMA VE SONUÇ}

Cilt lezyon bölütlemesinde eşikleme tabanlı yöntemler yaygın olarak kullanılmaktadır. Yapılan çalışmada klasik eşikleme yöntemi olan Otsu yönteminin metasezgisel yöntemler ile kullanılmasının bölütleme başarımından ödün vermeden daha az hesaplama süresinde gerçeklenebildiği gösterilmiştir. Geleneksel eşikleme yöntemleri hâlihazırda hızlı yöntemler olmakla birlikte görüntü veri kümesi gün geçtikçe artmakta olduğundan, artan hesaplama süresini azaltmak ciddi bir ihtiyaç olarak karşımıza çıkmaktadır. Yapılan çalışmada 20 iterasyon boyunca çalıştırılan PSO, HA ve 23 iterasyon çalışan SA metotları geleneksel Otsu yöntemine göre bölütleme başarımından ödün vermeden sırası ile \%12, \%7, \%18 daha hızlı olarak çözüme ulaşmışlardır. Burada zaman açısından en iyi çözümlere sırasıyla SA, PSO, HA ve Otsu yöntemlerinin ulaştığı görülmüştür. Ancak yöntemlerin ortalama iterasyon sayıları göz önüne alındığında bu durum değişmektedir.

PSO ve HA en iyi çözümü en iyi 2 en kötü 7 iterasyonda bulurken, SA en iyi 8 en kötü 22 adımda bulmuştur. Çalışmada PSO, HA, SA en iyi eşik değerini sırasıyla ortalama 4, 5, 17 iterasyonda bulmuştur. Ortalama iterasyon sayılarına bakıldığında PSO, HA ve SA'nın geleneksel Otsu yöntemine göre sirasıyla \%40, \%29, \%28.5 daha hızlı olduğu gözlemlenmiştir. Ayrıca bu sonuca bakıldığında sürü optimizasyonu mantığıyla çalışan PSO ve HA algoritmalarının tekil optimizasyon yapan SA yöntemine göre çözüme çok daha hızlı ulaştığ anlaşılmıştır.

Elde edilen sonuçlar incelendiğinde, gerek global gerek adaptif eşikleme yöntemlerinde metasezgisel yöntemlerin kullanılmasının, yanıt süresini önemli ölçüde azalttığı sonucuna varılmıştır. Klasik otsu 
yöntemi metasezgisel yöntemlere kıyasla amaç fonksiyonunu daha kısa sürede hesaplayabilmesine rağmen, en iyi amaç fonksiyon değerine ulaşabilmek için arama uzayının tamamını aramak durumunda kalmıştır. $\mathrm{Bu}$ durum daha karmaşık algoritmalar içeren metasezgisel yöntemlerin arama uzayında uygun değer sonuca az sayıda iterasyon ile ulaşmasını sağlamıştır. Gelecekteki çalışmalarda yaygınlaşan derin öğrenme mimarisiyle ortaya çıan parametre optimizasyon problemlerinin metasezgisel yöntemlerle ele alınması planlanmaktadir.

\section{KAYNAKLAR}

[1] M. Silveira et al., "Comparison of segmentation methods for automatic diagnosis of dermoscopy images.," Conf. Proc. IEEE Eng. Med. Biol. Soc., vol. 3, no. 1, pp. 6573-6576, 2009.

[2] Y. Yuan, M. Chao, and Y. C. Lo, “Automatic Skin Lesion Segmentation Using Deep Fully Convolutional Networks with Jaccard Distance," IEEE Trans. Med. Imaging, vol. 36, no. 9, pp. 1876-1886, 2017, doi: 10.1109/TMI.2017.2695227.

[3] W. Stolz, A. Reimann, and A. B. Cognetta, "ABCD rule of dermatoscopy: a new practical method for early recognition of malignant melanoma." 1994.

[4] G. Argenziano et al., "Seven-point checklist of dermoscopy revisited," Br. J. Dermatol., vol. 164, no. 4, pp. 785-790, 2011, doi: 10.1111/j.1365-2133.2010.10194.x.

[5] S. W. Menzies, An atlas of surface microscopy of pigmented skin lesions: dermoscopy. McGraw-Hill, 2003.

[6] R. J. Al-Azawi, A. A. Abdulhameed, and H. M. Ahmed, "A Robustness Segmentation Approach for Skin Cancer Image Detection Based on an Adaptive Automatic Thresholding Technique," Am. J. Intell. Syst., vol. 2017, no. 4, pp. 107112, 2017, doi: 10.5923/j.ajis.20170704.01.

[7] R. Garnavi, M. Aldeen, M. E. Celebi, G. Varigos, and S. Finch, "Border detection in dermoscopy images using hybrid thresholding on optimized color channels," Comput. Med. Imaging Graph., vol. 35, no. 2, pp. 105-115, 2011, doi: 10.1016/j.compmedimag.2010.08.001.

[8] B. Erkol, R. H. Moss, R. J. Stanley, W. V Stoecker, and E. Hvatum, "Images Using Gradient Vector Flow Snakes," Ski. Res. Technol., pp. 17-26, 2005.

[9] T. F. Chan, B. Yezrielev Sandberg, and L. A. Vese, "Active contours without edges for vectorvalued images," J. Vis. Commun. Image Represent., vol. 11, no. 2, pp. 130-141, 2000, doi: 10.1006/jvci.1999.0442.

[10] A. Agarwal, A. Issac, M. K. Dutta, K. Riha, and V. Uher, "Automated skin lesion segmentation using k-Means clustering from digital dermoscopic images," in 2017 40th International Conference on Telecommunications and Signal Processing, TSP 2017, 2017, vol. 2017-January, pp. 743-748, doi: 10.1109/TSP.2017.8076087.

[11] A. Wong, J. Scharcanski, and P. Fieguth, "Automatic skin lesion segmentation via iterative stochastic region merging," IEEE Trans. Inf. Technol. Biomed., vol. 15, no. 6, pp. 929-936, 2011 ,

10.1109/TITB.2011.2157829.

[12] N. K. El Abbadi and A. H. Miry, "Automatic segmentation of skin lesions using histogram thresholding," J. Comput. Sci., vol. 10, no. 4, pp. 632-639, 2014,

10.3844 jcssp.2014.632.639.

[13] M. Aljanabi, Y. E. Özok, J. Rahebi, and A. S. Abdullah, "Skin lesion segmentation method for dermoscopy images using artificial bee colony algorithm," Symmetry (Basel)., vol. 10, no. 8, 2018, doi: 10.3390/sym10080347.

[14] R. Eberhart and J. Kennedy, "New optimizer using particle swarm theory," Proc. Int. Symp. Micro Mach. Hum. Sci., pp. 39-43, 1995, doi: 10.1109/mhs.1995.494215.

[15] H. Doğan, S. Ayas, E. Gedikli, and M. Ekinci, "Parçacık Sürü Zekası Optimizasyonu ile Mikroskobik Görüntülerin Segmentasyonunda Farklı Entropi Ölçülerinin Etkisi," Süleyman Demirel Üniversitesi Fen Bilim. Enstitüsü Derg., vol. 22, no. 2, p. 703, 2017, doi: 10.19113/sdufbed.64012.

[16] S. Kirkpatrick, C. D. Gelatt, and M. P. Vecchi, Optimization by Simulated Annealing. Morgan Kaufmann Publishers, Inc., 1987.

[17] N. Metropolis, A. W. Rosenbluth, M. N. Rosenbluth, A. H. Teller, and E. Teller, "Equation of state calculations by fast computing machines," J. Chem. Phys., vol. 21, no. 6, pp. 1087-1092, 1953, doi: 10.1063/1.1699114.

[18] Z. W. Geem, "1-D Optimization Algorithms," Optimization, pp. 35-54, 2001, doi: 10.1201/b18469-3.

[19] B. Kamişlioğlu and N. Karaboğa, "Lower Order System Modelling with Harmony Search Algorithm," pp. 576-580, 2012.

[20] N. Otsu, "Pourazowe zniekształcenie przednich zebów stałych i zwiazane $\mathrm{z}$ tym trudności lecznicze.," Czas. Stomatol., vol. 26, no. 8, pp. 855-860, 1973. 